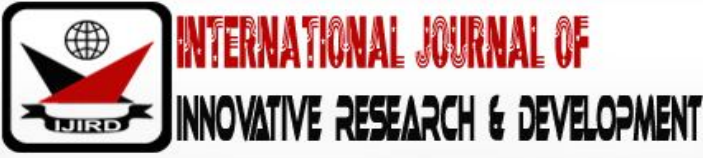

ISSN 2278 - 0211 (Online)

\section{University Students and Lecturers Perceptions towards the Use of Group Assignment in Assessing Learning Outcomes: A Case of Mwenge Catholic University, Tanzania}

Joseph Mushi Lidya
Assistant Lecturer, Department of Education Foundation, Mwenge Catholic University, Tanzania
Joseph Lasway Angelista
Assistant Lecturer, Department of Education Curriculum Instruction, Mwenge Catholic University, Tanzania

\begin{abstract}
:
Teaching and learning in all levels of education continues to be complex process which involve innovations, creativity, critical thinking and other skills to make it meaningful. The process of determining effective learning has become challenging to most of the instructors and the target learners at various levels. The current study investigates the perception of university students and their lecturers in the use of group assignment as an assessment technique in the teaching and process. The significance of the study was to find out how both students and lecturers perceive the group assignment tasks used in assessing learning at the university. The study aimed at finding answers of the following questions: what are the perceptions of Mwenge Catholic University (MWECAU) students and lecturers towards the use of group assignment as an assessment technique in the teaching and learning process; to what extent is the use of group assignment significant in assessing students' learning and what is the students' preferred assessment techniques to be used in learning process. A cross sectionalsurvey research design under the quantitative research approach was used to guide the study. Simple random sampling technique was used to select 400 students and 20 lecturers from Mwenge Catholic University who participated in the study. Data was collected using a questionnaire with open and closed questions. The analysis of data was conducted by using descriptive and inferential statistics presented as frequencies, percentage and mean for numerical data and descriptions for the open-ended items while information was presented through statistical tables. The findings indicate that there is a slight difference in students and lecturers mean perceptions towards the use of group assignment when used as assessment technique. Group assignment technique was perceived to have advantages to both students and lecturers in various dimensions. Among the advantages identified is promotion of students' confidence, communication skills, and as an easy way of students scoring good marks and simplified marking for the lecturers. On the other hand, participants pointed out that the use of group assignment as assessment technique encourages students' to be negligent, plagiarism, dependency, domination by higher achievers and others. The study concludes that the use of group assignment helps to develop more of social skills than the academic competence. Therefore, if used, it should be well organized to capture different learning abilities and follow-up initiatives to attain students' participation and objectives for learning. Authors of the study recommend that the lecturers be equipped with necessary skill for forming balanced groups which involve all the categories of learners' abilities and enhances participation in the group tasks.
\end{abstract}

Keywords: Assessment technique, group assignment, teaching and learning

\section{Introduction}

In education, the term assessment refers to the wide variety of methods or tools that educators use to measure, evaluate, and document the academic readiness, learning progress, skill acquisition, or educational needs of students (Great School Partnership, 2014). Teachers used assessment as a method of identifying individual students' weaknesses and strengths so that they can provide required educational support to the particular student. The purpose of assessment differs from one teacher to another or one school to another. It also depends on how it is designed and how it is used. Assessment helps teachers to identify what children know, children with special needs, appropriate placement and appropriate curricula to meet children's individual needs.

Generally, assessment for learning provides students with information and guidance so that they can plan and manage the next steps in their learning. This is supported by Eberly Center (2016) argued that, since learning takes place in students' 
heads where it is invisible to others, learning must be assessed through performance, that is what students can do with their learning.

Assessment for learning uses information to lead from what has been learned to what needs to be learned next. Furthermore, assessment helps teachers gather information to plan and modify teaching and learning programmes for individual students, groups of students, and the class as a whole. Through assessment teachers identify students' learning needs in a clear and constructive way so that they can be addressed and eventually involve parents and families about their children's learning. There are several assessment tools used by teachers during teaching and learning. Such tools include class tests, student's presentation, oral questions, minute paper, stepping stone, hot seat, hat trick, student's summary and many others. Eberly (2016) study mentions some common assessment tools such as assignments, examinations, concept map, tests, group work and others. Therefore, it is the task of the teachers to find the effective assessment method which fits their students by considering some factors such as a student's level, availability of the teaching and learning material, classroom environment, time, students learning style, and the purpose of the assessment.

This shows that assessment is part of the teaching and learning process and teachers get the feedback of their teaching style through students' assessment. Bhaskar (2013) revealed that since assessment is an integral part of instruction and it determines whether or not the learning standards are being met, it enables educators to know the extent to which teaching strategies are helpful to students. Secondary schools are among the education institutions which use different assessment methods to determine the extent to which students acquired the intended learning outcomes.

UNESCO (2018) in the study on the use of student's assessments for policy and learning improvements found that, the increased pressure in the enrollment of students in the learning institutions including the universities promote teachers to apply assessment techniques that are more convenient for marking and scoring. This pressure leads to increased workloads and time for consultation which brings about teacher to use group activities such as group assignment technique among others. Therefore, this study investigates the students and lecturer's perceptions towards the use of group assignment in assessing learning outcomes.

\subsection{Research Questions}

- What are the perceptions of MWECAU students towards the use of group assignment as an assessment technique in the teaching and learning process?

- What are MWECAU lecturers' perceptions towards the use of group assignment technique in assessing students learning?

- To what extent is the use of group assignment effective in assessing students' learning?

- What is the students' most preferred assessment technique used in the learning process?

\subsection{Research Hypothesis}

There is a significant difference between mean scores of MWECAU university lecturers and students' perception towards the use of group assignment as an assessment tool.

\subsection{Theory of Learning by Brunner 1960s}

The theory of constructivism by Brunner emphasizes the active engagement of learners in the teaching and learning process. The theory maintains that learners construct meaning and make sense of the world through mental processes. In teaching the teacher applies different teaching and assessment techniques to facilitate the acquisition of knowledge, skills, values and attitudes in order to develop holistic learning. In the process teacher's perspective require to select teaching methods and assessment tools which promote active students' engagement and encourage problem solving-skills.

The implication of the theory requires the instructors to design approaches which make their learners to be mentally and socially able to solve problems related to knowledge and skills. In this study therefore, the authors intended to determine the extent to which group discussion learning activity enhances knowledge and skill acquisition and its powerfulness in providing assessment feedback.

Vygotskys' socio-cultural theory (1978) emphasizes the role of collaborative learning and team-based skills in the learning process. The theory encourages more knowledgeable learners to share their knowledge with their peers and bring about challenges in the teaching and learning process. In this theory, role of the instructor is to stimulate learning in terms of helping the learners to uncover and address gaps and misconceptions in knowledge and skills. The theories' framework shows that the social interaction plays a fundamental role in the development of cognition and therefore instructors must establish approaches to enhance this interaction during the teaching and learning processes. The main focus in the theory is that learning becomes more constructive if it engages two or more people in a critical environment. Thus, in this this paper group assignment technique reflects this framework.

\section{Methodology}

A case study design was applied in this study whereby only one institution was selected as reference in order to obtain detailed information. The target population was one university, 5000 university students and 105 lecturers. Simple random sampling technique was applied to select 400 students and 20 university lecturers at MWECAU. Data was collected through questionnaire with closed and open-ended questions. The collected data were analyzed by using qualitative and 
quantitative approaches whereby descriptive and inferential statistics were employed. The information was summarized into frequencies, percentage and means. The qualitative data were organized into themes and narrated. The hypothesis was tested through independent t-test to establish the difference between mean scores of MWECAU university lecturers' and students' perceptions towards the use of group assignment as an assessment tool.

\section{Findings and Discussion}

The authors in this study sought to find out the perception of students towards the use of group assignment as a method of assessment. Data collected through questionnaire from the students were analyzed and summarized as shown in Table 1.

\begin{tabular}{|c|c|c|c|c|c|c|c|c|c|c|c|}
\hline & Statement & \multicolumn{2}{|c|}{ Sa } & \multicolumn{2}{|c|}{$\mathbf{A}$} & \multicolumn{2}{|c|}{$\mathbf{U}$} & \multicolumn{2}{|c|}{ D } & \multicolumn{2}{|c|}{ Sd } \\
\hline & & $\mathrm{F}$ & $\%$ & $\mathrm{~F}$ & $\%$ & F & $\%$ & $\mathrm{~F}$ & $\%$ & $\mathrm{f}$ & $\%$ \\
\hline 1 & It encourages students confidence & 242 & 60.5 & 148 & 37 & - & - & 3 & 1 & 6 & 1.5 \\
\hline 2 & Demands time during preparation & 180 & 45 & 183 & 45.8 & 7 & 1.8 & 27 & 6.8 & 3 & 8 \\
\hline 3 & $\begin{array}{l}\text { Create negligence among some } \\
\text { students }\end{array}$ & 101 & 25.3 & 202 & 50.5 & 17 & 4.3 & 50 & 12.5 & 30 & 7.5 \\
\hline 4 & It encourages plagiarism & 122 & 30.5 & 182 & 45.5 & 24 & 5 & 53 & 13.3 & 19 & 4.8 \\
\hline 5 & Few students dominate the groups & 131 & 32.8 & 194 & 48.5 & 2 & 5 & 46 & 11.5 & 27 & 6.8 \\
\hline 6 & $\begin{array}{l}\text { It promotes bias to higher achievers } \\
\text { and committed students }\end{array}$ & 147 & 36.8 & 178 & 44.5 & 11 & 2.8 & 49 & 12.3 & 15 & 3.8 \\
\hline 7 & $\begin{array}{l}\text { Limit participation among some } \\
\text { students }\end{array}$ & 143 & 35.8 & 188 & 47 & 13 & 3.3 & 42 & 10.5 & 14 & 3.5 \\
\hline 8 & $\begin{array}{l}\text { Promote rote-learning since students } \\
\text { memorize for presentation }\end{array}$ & 121 & 30.3 & 207 & 51.8 & 6 & 1.5 & 45 & 11.3 & 21 & 5.3 \\
\hline 9 & $\begin{array}{l}\text { It is used by students as an easy way } \\
\text { of scoring marks }\end{array}$ & 125 & 31.3 & 176 & 44.8 & 16 & 4 & 58 & 14.5 & 22 & 5.5 \\
\hline 10 & $\begin{array}{c}\text { It is not trustworthy technique for } \\
\text { assessment }\end{array}$ & 137 & 34 & 172 & 43 & 3 & 8 & 49 & 12.3 & 39 & 11.3 \\
\hline 11 & $\begin{array}{l}\text { It discourages the hardworking } \\
\text { students }\end{array}$ & 132 & 33 & 171 & 42.8 & 4 & 1 & 48 & 12 & 45 & 11.3 \\
\hline 12 & $\begin{array}{l}\text { Difficulty to organize balanced } \\
\text { groups based on the students' } \\
\text { abilities }\end{array}$ & 141 & 35.5 & 210 & 52.5 & 8 & 2 & 37 & 9.3 & 4 & 1 \\
\hline 13 & $\begin{array}{l}\text { It becomes difficult to determine the } \\
\text { owner of the group work }\end{array}$ & 124 & 31 & 180 & 45 & 19 & 4.8 & 56 & 14 & 21 & 5.3 \\
\hline 14 & $\begin{array}{l}\text { It is difficult to discriminate student's } \\
\text { ability based on their efforts }\end{array}$ & 174 & 44.5 & 175 & 43.8 & - & - & 41 & 10.3 & 6 & 1.5 \\
\hline 15 & $\begin{array}{l}\text { It is the most effective method of } \\
\text { assessment }\end{array}$ & 18 & 4.5 & 58 & 14.5 & 12 & 3 & 205 & 51.3 & 107 & 26.8 \\
\hline 16 & $\begin{array}{l}\text { It encourages students to use the } \\
\text { library }\end{array}$ & 130 & 32.5 & 173 & 43.3 & 17 & 4.3 & 53 & 13.3 & 27 & 6.8 \\
\hline 17 & $\begin{array}{l}\text { Improves students communication } \\
\text { skills }\end{array}$ & 166 & 41.5 & 166 & 41.5 & 183 & 45.8 & 39 & 9.8 & 12 & 3 \\
\hline 18 & $\begin{array}{l}\text { It is easy method of assessing } \\
\text { students when having a large class }\end{array}$ & 182 & 45.5 & 175 & 43.8 & 7 & 1.8 & 27 & 6.8 & 9 & 2.3 \\
\hline 19 & $\begin{array}{l}\text { Some students pay for printing the } \\
\text { work but not participate in doing it }\end{array}$ & 182 & 45.5 & 175 & 43.8 & 7 & 1.8 & 27 & 6.8 & 9 & 2.3 \\
\hline 20 & $\begin{array}{c}\text { It is difficult for students to meet } \\
\text { deadline }\end{array}$ & 85 & 21.3 & 178 & 44.5 & 16 & 4 & 100 & 25 & 21 & 5.3 \\
\hline
\end{tabular}

Table 1: Students' Perception on the Use of Group Assignment as an Assessment Tool

The findings show that approximately $60.5 \%$ and $37 \%$ of the students' participants respectively had the perception that group assignment promotes confidence. This implies that group assignment activities provide opportunities for students to demonstrate their abilities during presentation and in this way, it promotes their confidence. Ziemba and Columbus (2007) support the use of methods which promotes confidence to students because they are engaged in presentation tasks such as in group assignment among others. Assessment through group assignment was perceived as consuming a lot of time during its preparation and this was demonstrated by $45 \%$ and $45.8 \%$ of students' participants respectively. Based on this result group assignment was found to be a hectic approach which requires learners to spend more time to do it as compared to other assessment techniques. 
The findings show that $80 \%$ of the students either disagreed or strongly disagreed that use of group assignment encourages students to use the library. The results imply that students do not use the library because they can access information from other sources of information and find answers for their group assignment. The finding concurs with a study by Kumah (2015) who found that university students prefer use of internet materials rather than the library sources. On the other hand, $98 \%$ of the respondents either strongly agreed or agreed that it is difficult to organize balanced groups based on the students' abilities. This might be due to the large number of students and the criteria employed by lecturers in forming the groups whereby subject combinations or lecture groups are used as basis. About $89.3 \%$ of the students either strongly agreed or agreed that it is an easy method of assessing students when having a large class. This shows that teachers use the group assessment to reduce tiresome process of making individual work and meet the deadline for submitting the coursew ork result to the appropriate office. The same $89.3 \%$ of the students either agreed strongly or agreed that some of the students in the group pay the cost for printing the work but not participate in doing the assignment. This implies that if lecturers are not strictly following the progress of the groups, student's participation becomes low during preparation of the group assignment. The findings show however that, it is difficult to discriminate students' ability based on their efforts during the formation of the groups and this was indicated by $88.3 \%$ of the students' respondents who either strongly agreed or agreed with the argument. On the other hand, 83\% agreed and strongly agreed that group assignments improve students' communication skills but $82.8 \%$ responded that it limits participation among students. This could be due to the reason that some students do not have good background in written and spoken English language. A study by Carnegie Mellon University (2016) suggests that group assignments help students to develop strong communication skills, coordination and conflict resolution techniques. About $82.1 \%$ said that group assignments promote rote-learning, since students only memorize for presentation while $81.3 \%$ revealed that the method encourages some students' domination and promote bias to higher achievers. This finding indicates that the role of group assignment as a technique of assessing learning is diminishes because it does not provide learners with the intended objectives. The results above reflect that $78.1 \%$ either strongly disagree or disagree that the method is effective for assessment.

The responses revealed that $76 \%$ either strongly agreed or agreed that it is difficult to determine the owner of the group work as well as encourages plagiarism and it is perceived by students as an easy way of scoring marks by low performance thus makes it to be less trustworthy technique for assessment. Furthermore, the findings indicate that $75.8 \%$ of students' respondents that group assignment creates negligence among the students and discourage the hard-working students respectively. The use of group assignment leads to difficulties for students to meet set deadlines for submission of their work for presentation and scoring. However, the results reflect the reality of what happens when students are assigned group activities which is difficult for lecturers to manage its progress and performance.

On the other hand, researchers used the Likert scale to find the lecturers' perceptions on the use of the group assignment as students' assessment method. The following are the responses as shown in Table 2.

\begin{tabular}{|c|c|c|c|c|c|c|c|c|c|c|}
\hline Responses & \multicolumn{2}{|c|}{ SA } & \multicolumn{2}{|c|}{$\mathbf{A}$} & \multicolumn{2}{|c|}{$\mathbf{U}$} & \multicolumn{2}{|c|}{$\mathbf{D}$} & \multicolumn{2}{|c|}{ SD } \\
\hline & $\mathrm{f}$ & $\%$ & $\mathrm{f}$ & $\%$ & $\mathrm{f}$ & $\%$ & $\mathrm{f}$ & $\%$ & $\mathrm{f}$ & $\%$ \\
\hline It encourages students confidence & 9 & 60 & 3 & 20 & 1 & 6.7 & 1 & 6.5 & 1 & 6.7 \\
\hline Demands time during preparation & 3 & 20 & 10 & 66.7 & & & 2 & 13.3 & & \\
\hline It encourages negligence among some students & 4 & 26.7 & 5 & 33.3 & 2 & 13.3 & 2 & 13.3 & $\overline{2}$ & 13.3 \\
\hline It encourages plagiarism & 2 & 13.5 & 8 & 53.3 & 1 & 6.7 & 3 & 20 & 1 & 6.7 \\
\hline Few students dominate the groups & 5 & 33.3 & 9 & 60 & 1 & 6.7 & & & & \\
\hline $\begin{array}{l}\text { It promotes bias to higher achievers and committed } \\
\text { students }\end{array}$ & 5 & 33.3 & 6 & 40 & 2 & 13.3 & $\overline{1}$ & 6.7 & $\overline{1}$ & 6.7 \\
\hline Limits participation among some students & 2 & 13.3 & 8 & 53.3 & 1 & 6.7 & 4 & 26.7 & & \\
\hline $\begin{array}{c}\text { Promotes rote learning since students memorize for } \\
\text { presentation }\end{array}$ & 1 & 6.7 & 4 & 26.7 & - & - & 9 & 60 & $\overline{1}$ & 6.7 \\
\hline $\begin{array}{l}\text { It is used by students as an easy } \\
\text { way of scoring marks }\end{array}$ & 2 & 13.3 & 7 & 46.7 & 1 & 6.7 & 3 & 20 & 2 & 13.3 \\
\hline It is not trustworthy technique for assessment & & & 3 & 20 & 4 & 26.7 & & 40 & 2 & 13.3 \\
\hline It discourages the hard-working students & 2 & 13.3 & 6 & 40 & 3 & 13.3 & 4 & 26.7 & 1 & 6.7 \\
\hline $\begin{array}{c}\text { Difficult to organize balanced groups based on the } \\
\text { students' abilities }\end{array}$ & 2 & 13.3 & 8 & 53.3 & 2 & 13.3 & 3 & 20 & _ & _- \\
\hline $\begin{array}{l}\text { It becomes difficult to determine the owner of the } \\
\text { group work }\end{array}$ & 3 & 20 & 9 & 60 & 1 & 67 & 2 & 13.3 & 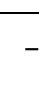 & 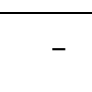 \\
\hline $\begin{array}{c}\text { It is difficult to discriminate student's ability based } \\
\text { on their efforts }\end{array}$ & 2 & 13.3 & 6 & 40 & 1 & 6.7 & 5 & 33.3 & 1 & 6.7 \\
\hline It is an easy the most effective method of assessment & 1 & 6.7 & 5 & 33.3 & 2 & 13.3 & 6 & 40 & 1 & 6.7 \\
\hline
\end{tabular}




\begin{tabular}{|c|c|c|c|c|c|c|c|c|c|c|}
\hline \multirow[t]{2}{*}{ Responses } & \multicolumn{2}{|c|}{ SA } & \multicolumn{2}{|c|}{$\mathbf{A}$} & \multicolumn{2}{|c|}{$\mathbf{U}$} & \multicolumn{2}{|c|}{ D } & \multicolumn{2}{|c|}{ SD } \\
\hline & $\mathrm{f}$ & $\%$ & $\mathrm{f}$ & $\%$ & $\mathrm{f}$ & $\%$ & $\mathrm{f}$ & $\%$ & $\mathrm{f}$ & $\%$ \\
\hline It encourages students to use the library & - & - & 11 & 73.3 & - & - & 3 & 20 & 1 & 6.7 \\
\hline Improves students communication skills & 2 & 13.3 & 9 & 60 & 3 & 20 & 1 & 6.7 & - & - \\
\hline $\begin{array}{c}\text { It is easy method of assessing and marking students } \\
\text { when having a large class }\end{array}$ & 5 & 33.3 & 7 & 46.7 & 1 & 6.7 & 1 & 6.7 & 1 & 6.5 \\
\hline $\begin{array}{l}\text { Some students pay for printing the work but not } \\
\text { participate in doing it }\end{array}$ & 7 & 46.7 & 2 & 13.3 & 2 & 13.3 & 2 & 13.3 & 2 & 13.3 \\
\hline It is difficult for students to meet deadline & 3 & 20 & 1 & 6.7 & 3 & 20 & 5 & 33.3 & 3 & 20 \\
\hline
\end{tabular}

Table 2: Lecturers' Perception on the Use of Group Assignment as an Assessment Tool

The Lecturers' perception shows that 93.3\% responded that few students dominate groups during the activity. The method here is found to favor few students and therefore does not bring about a change in behaviour to all students participating. The findings show 86.7 either strongly agreed or agreed that the technique demands time during preparation and the implication is that the method demands for students' commitment and dedication to work in groups during their extra time. However, $80 \%$ of the lecturers who participated in the study agreed strongly or agreed that it is difficult to determine the owner of the group work but it is easy method of marking and assessing students in large class size. The findings also show that $73.3 \%$ of lecturers strongly agreed or agreed that the use of the method helps to improve communication skills among the students while the same percentage indicates that the method promotes bias to higher achievers and committed students.

The results in the table above show that $66.8 \%$ of lecturers strongly agreed or agreed that the use of the method encourages plagiarism while $66.7 \%$ disagreed that the method promotes rote-learning among students since they memorize the facts for presentation only. This implies that the method does not encourage creativity and critical reasoning which is one of the purposes of learning. The results support the findings indicated in the study by the University of Dublin (2018) which found the same challenge in students' cooperative learning groups. The study emphasizes that group assignment can also be hard to assess whether there is specific individual contribution. Furthermore, the findings indicate that $66.6 \%$ of lecturers either strongly agreed or agreed that the use of group assignment limits students' participation and also it is difficult to organize balanced groups based on the students' ability. According to table 2 above $60 \%$ of participants either agreed strongly or agreed that group assignment method encourages student's confidence but some of students do not participate in doing the work rather they pay for the printing of the final document only. The finding is in support of a study by Falchikou (2005) who asserts that some group members score high marks on the basis of other hardworking group members. On the other hand, $60 \%$ strongly agreed and agreed that it is easy to score the group works rather than individual task because it saves time. This implies that group assessment method is used most of the time because it makes easy the processing of course works for students in large classes. The method also creates laziness among some students which brings about overdependence of negligent students resulting in ineffective teaching and learning process.

The findings show that $53.3 \%$ of lecturers agreed strongly or agreed that the use of group assignment discourages hardworking student. The same percentage also showed that it is difficult to discriminate students' ability and delays students in meeting deadlines. On the other hand, the same percent (53.3\%) of lecturers disagreed strongly or disagreed that group assignment is not trustworthy assessment technique. The findings indicate that some lecturers (40\%) disagreed that group assignment is the most effective method of assessing students learning while $40 \%$ strongly agreed or agreed with the statement. Generally, the findings from both lecturers and students showed positive and negative perception towards the use of group assignment as an assessment technique in some aspects in the learning process.

\subsection{Advantages of Using Group Work}

The researchers in this work sought to find out the advantages of using group assessment in determining the learning progress of learners. The following information was obtained when data was collected through questionnaire from the students. 


\begin{tabular}{|c|c|c|c|}
\hline $\mathbf{1}$ & Advantage & $\mathbf{f}$ & $\mathbf{\%}$ \\
\hline 2 & Increases students confidence through presentation & 98 & 24.5 \\
\hline 3 & Fosters students participation & 31 & 7.75 \\
\hline 4 & Increases students creativity & 59 & 14.75 \\
\hline 5 & It saves time & 28 & 7.0 \\
\hline 6 & Increases students exposure & 198 & 49.5 \\
\hline 7 & Increases students interaction & 201 & 50.25 \\
\hline 8 & Students discover new things & 56 & 14 \\
\hline 9 & Increases students' social relations & 158 & 39.5 \\
\hline 10 & Increases students' cooperation & 73 & 18.25 \\
\hline 11 & Develops students' new knowledge & 48 & 12 \\
\hline & It enables sharing between students & 78 & 19.5 \\
\hline
\end{tabular}

Table 3: Shows the Distribution of Participants' Responses on the Advantages of

Group Assignment in Assessing Learning

The findings in the Table 3 show that there are various advantages of using group assignment techniques in assessing university students learning progress. About $50 \%$ of the students' responses indicate that the use of group assignment increases students' interaction, and exposure respectively. This finding implies that most of the advantages have social significance than the academic intentions. In general, the use of the technique saves time for marking and enhances students sharing.

Other respondents $(24.5 \%)$ show that the group assignment method increases students' confidence since they are involved in presentations and receive feedback from the rest of the class. Therefore, according to these respondents, the role of group assignment seems to be lower as they do not contribute much in the development of new knowledge because some of the students do not take it seriously. This finding though concurs with Jackson, Sibson and Riebe (2014) who found that learning in collaborative groups has higher influence in the acquisition of knowledge.

Researchers were interested to identify the assessment methods preferred by the students as the best way of assessing their learning progress and the following

\begin{tabular}{|c|c|c|c|}
\hline S/ N & Favorite Assessment Method & F & \% \\
\hline 1 & Individual test & 376 & 94 \\
\hline 2 & Quizzes & 107 & 26.75 \\
\hline 3 & Oral test & 47 & 11.75 \\
\hline 4 & Individual assignment & 219 & 54.75 \\
\hline 5 & Practical work & 43 & 10.75 \\
\hline
\end{tabular}

Table 4: Preferred Assessment Methods Identified by the Students

The findings for this item indicate that participants had preference for different assessment techniques other than group assignment which is the focus of this study. The information obtained reflects that $54.75 \%$ of participants identified the individual tests to be the most preferred technique. This response reveals that students show preference to the independent assessment techniques because it builds ones learning ability to remember and understand and analyze concepts which makes meaning that encourages independent learning. On the other hand, $26.75 \%$ of respondents said that they prefer quiz while others identified oral test and practical test respectively.

\subsection{Hypothesis Test}

Null hypothesis: There is no significant difference between mean scores of MWECAU university lecturers' and students' perceptions towards the use of group assignment as an assessment tool.

\begin{tabular}{|c|c|c|c|c|c|c|}
\hline Group & $\mathbf{N}$ & Mean & $\begin{array}{c}\text { Std } \\
\text { deviation }\end{array}$ & $\mathbf{T}$ & $\mathbf{d f}$ & Sg \\
\hline Lecturers & 20 & 3.9148 & 0.41092 & -3.658 & 14.987 & 0.002 \\
\hline Students & 400 & 3.5200 & 0.3951 & & & \\
\hline
\end{tabular}

Table 5: Showing Hypothesis Testing

Since the $\mathrm{p}$ value (0.002) is less than Alpha level (0.05) therefore the null hypothesis is rejected. There is significant difference between mean scores of MWECAU university lecturers and students' perceptions towards the use of group assignment as an assessment tool. 


\section{Conclusion}

The findings in this study conclude that there were slight differences in lecturers' and students' perceptions towards the use of group assignment as a method of assessment of the teaching and learning process. Therefore, the study findings indicate that students' assessment methods in higher learning institutions have to be varied in order to bring about effecting learning that is multiple assessment techniques applied.

\section{Recommendations}

Authors of this study recommend that in the teaching and learning process lecturers, regardless of their class size should find follow-up mechanisms when applying group assignment technique in order to make it effective. The method can also be improved through proper organization and monitoring of the groups which will in turn increase students' participation.

\section{References}

i. Barkley, E.F., Cross, K.P., \& Major, C.H. (2005). Collaborative learning techniques. San Francisco: Jossey-Bass.

ii. Bhaska, S. K. (2013). The best Assessment Techniques Used by Educators in the Classroom.Delhi: India.

iii. Boud, D. \& Falchikov, N. (2007). Rethinking assessment in the learning for the longer term.Abingdon: Routledge.

iv. Carnegie Mellon University (2016). Teaching Excellence and Educational inn. : Pittsburgh: Eberly Centre.

v. Falchikov, N.(2005). Improving Assessment through Student Involvement. London: Routledge.

vi. Jackson, D., Sibson, R., \& Riebe, L. (2014). Undergraduate perceptions of the development ofteam-working skills. Education+Training, 56(1), 7-20.

vii. Kumah, C.H. (2015). A comparative study of the use of the library and the internet as the sourceof information. University of Nebraska: Lincoln.

viii. Oxford Brookes University. (n.d.). ASKe: Groupwork Assessment. Retrieved on 3 July 2018 from http:/ / www.brookes.ac.uk/ aske/ Groupwork\%20Assessment.

ix. UNESCO (2013). The use of student assessment for policy and learning improvement: Educational policy Research working Document. Thailand: Bangkok.

x. University of Dublin (2018). Using Group Work as Assessment Method:Dublin.

xi. Ziemba, L. and Columbus N.E. (2017). Increasing students confidence and Knowledge Through Students Presentation. University of Nebraska:Licoln. 